\title{
Selective attentional delays and attentional capture among simultaneous visual onset elements
}

\author{
LISA R. FOURNIER \\ University of Illinois, Urbana-Champaign, Champaign, Illinois
}

\begin{abstract}
Visual discrimination and detection responses to a single stimulus presented simultaneously with noise stimuli are slower and less accurate than are responses to a single stimulus presented alone. This occurs even though the location of the relevant stimulus (target) is known or visually indicated with stimuli onset. Results showed that noise elements delay focal attending and processing of a target. Furthermore, precuing the target location reduces, and can eliminate, target processing delays. Processing delays were not due to response competition or to random attentional capture by noise. It is suggested that simultaneous stimuli are perceived initially as a single object, and delays in processing a single stimulus are due to difficulties in perceptually segregating this stimulus from noise. Precuing is assumed to facilitate this segregation process.
\end{abstract}

Briefly presented visual displays in which a subject is required to attend and respond to one stimulus (target) and ignore other stimuli (noise) have been used to study aspects of visual selective attention. It has been found that when target and noise elements are presented simultaneously, attentional selectivity is unable to entirely eliminate the effects of noise; reaction time (RT) to detect or discriminate the target is increased and accuracy is decreased relative to when a single target is presented alone (Colegate, Hoffman, \& C. W. Eriksen, 1973; C. W. Eriksen \& B. A. Eriksen, 1979; C. W. Eriksen, Hamlin, \& Daye, 1973; Grice, Boroughs, \& Canham, 1984; Grice, Canham, \& Boroughs, 1984; Grice, Canham, \& Schafer, 1982). This has been shown to occur even though target and noise are equal with respect to visual acuity, are featurally very distinct, and are presented far enough apart to prevent lateral or contour interference (C. W. Eriksen et al., 1973; C. W. Eriksen \& Hoffman, 1972b, 1974; Kahneman, Treisman, \& Burkell, 1983). Studies emphasizing target detection and discrimination speed have shown that as the number of noise items simultaneously presented with the target increases, target RT increases and accuracy decreases (Egeth, Atkinson, Gilmore, \& Marcus, 1973; C. W. Eriksen \& Hoffman, 1972a; C. W. Eriksen \& Rohrbaugh, 1970; Estes \& Taylor, 1966; Francolini \& Egeth, 1979; Lappin \& Uttal, 1976; Logan, 1978; Schneider \& Shiffrin, 1977). This inability to eliminate target detection and discrimination

This research was supported by the United States Public Health Service Research Grant MH01206 to C. W. Eriksen. The author thanks Charles W. Eriksen, Gordon Logan, Brian Dyre, Steven Yantis, Lester Krueger, and two anonymous reviewers for their helpful comments in preparing this manuscript. Correspondence should be addressed to L. R. Fournier, Department of Psychology, University of Illinois, Urbana-Champaign, 603 East Daniel St., Champaign, IL 61820. interference by noise has been referred to as the display size effect or the distraction effect (Grice, Canham, \& Boroughs, 1984; Grice et al., 1982).

In visual search tasks, distraction effects may be related (in part) to increased time to locate the target when more noise elements are present, since the location of the target is uncertain (Treisman \& Gelade, 1980; Treisman \& Souther, 1985). However, distraction effects have been shown to occur even though perceptually the target appears to "pop out" among the noise elements (Kahneman et al., 1983). Moreover, distraction effects have been shown to occur in nonsearch tasks in which subjects should be able to easily locate the target (B. A. Eriksen \& C. W. Eriksen, 1974; C. W. Eriksen \& Hoffman, 1972a; C. W. Eriksen \& Schultz, 1978). In nonsearch tasks, subjects always know where the target will appear either because the target appears repeatedly in a specific location or because a salient visual marker indicates the target location before or simultaneously with display onset.

The purpose of the present study was to determine the cause of distraction effects in nonsearch tasks. Two possibilities are examined. The first suggests that the distraction effect is due to response priming by noise stimuli that may interfere with and slow target responses (response competition). The second suggests that the distraction effect is due to perceptual variables that make it difficult to segregate the target from noise that may delay attentional selection of the target. Although distraction effects within nonsearch tasks are of primary interest, variables affecting distraction effects in visual search will also be discussed, since these variables may also influence target selection in nonsearch tasks.

Distraction effects have been shown to be more extreme in nonsearch tasks when responses are based on choice discrimination as opposed to detection (Kahne- 
man et al., 1983). Grice and Canham (1990) have recently suggested that distraction decrements may be specific to choice RT tasks. When comparing RTs to a target presented alone and RTs to a target letter paired with a neutral noise letter (that did not have an assigned response), an increase in RT was found for the target paired with a noise letter in a choice RT task, but not in a go/no-go task. Grice and Canham claim that distraction effects may be a result of response competition from noise elements in choice RT tasks, even though noise elements may not have explicitly assigned responses (C. W. Eriksen \& St. James, 1986). The lack of a distraction effect in the go/no-go task was thought to be due to an absence of any possible response priming by noise. Kahneman et al. (1983), however, found slight distraction decrements in a go/no-go task. They found that detection of a word among nonsense shapes was slightly slowed as the number of nonsense shapes increased. The latter finding suggests that the distraction effect is not dependent on choice RT tasks. Moreover, there is doubt that go/no-go tasks completely eliminate response priming by noise (see Miller \& Hackley, 1992). Thus, although the distraction effect may not be limited to choice RT tasks, response competition is still a plausible explanation for distraction effects found in go/no-go tasks.

There is also evidence that the distraction effect is influenced by perceptual variables. Increasing targetnoise grouping by decreasing separation between target and noise (C. W. Eriksen \& Hoffman, 1972b; Estes, 1972,1982 ), by increasing feature similarity between target and noise (Bundesen \& Pedersen, 1983; C. W. Eriksen \& Hoffman, 1972b; Grunzke, 1991; Lockhead, 1979; Monahan \& Lockhead, 1977; Pomerantz \& Garner, 1973; Pomerantz \& Schwaitzberg, 1975) and by decreasing feature similarity among noise elements (Duncan \& Humphreys, 1989), has been shown to increase distraction effects in detection and discrimination tasks. Furthermore, Banks and Prinzmetal (1976) have shown that increasing the amount of noise can actually improve target detection if the added noise (holding target-noise proximity constant) increases the degree to which the noise form perceptual groups separate from the target. However, decreasing perceptual grouping among target and noise by minimizing target-noise proximity and target-noise feature similarity and by maximizing noise-noise similarity has only been shown to reduce, but not eliminate, distraction effects in nonsearch tasks (C. W. Eriksen et al., 1973; C. W. Eriksen \& Hoffman, 1972b; C. W. Eriksen \& Schultz, 1978; Kahneman et al., 1983).

Providing target location information in advance of stimulus presentation (precue) has also been shown to reduce the distraction effect (C. W. Eriksen \& Hoffman, 1973; C. W. Eriksen \& Rohrbaugh, 1970; Fournier \& C. W. Eriksen, 1990; Hoffman, 1975; Jonides, 1980 , 1981; Kahneman et al., 1983; Logan, 1978; van der Heijden, 1992). In addition, the greater the number of noise elements present in the display (or the greater proximity between target and noise), the more target discrimination RT is facilitated by precuing (C. W. Eriksen \& Hoffman, 1972a; Logan, 1978). Moreover, there is a suggestion that precuing may eliminate the distraction effect when target and noise are highly discriminable (Kahneman et al., 1983). ${ }^{1}$ However, C. W. Eriksen et al. (1973) found that when subjects knew the target location in absence of a location precue, noise elements continued to interfere with target discrimination.

Thus, location information alone does not appear to eliminate distraction effects, but precuing appears to greatly reduce distraction effects and may possibly eliminate them. Perhaps the precue is doing more than just providing target location information. It is proposed that precuing may reduce and eliminate the distraction effect by expediting the process of segregating the target from noise. Once the target is perceptually segregated from noise, focal attention may then be directed to the target. However, peripherally precuing a target location has not been found to eliminate distraction effects in two-choice response competition paradigms (Colegate et al., 1973; C. W. Eriksen \& Hoffman, 1973; Hoffman, 1975). ${ }^{2}$ This exception will be addressed in the General Discussion.

Further evidence suggesting that perceptual variables such as target-noise segregation may delay focal attending to the target is provided by Hoffman (1975) and Kahneman et al. (1983). They have shown that when a target temporally preceded (see also C. W. Eriksen \& Schultz, 1979) or followed noise at certain time intervals, distraction effects were eliminated. Yet, when abrupt onsets or offsets of noise occurred simultaneously with abrupt target onset, target RTs increased relative to target RTs when a target was presented alone (Kahneman et al., 1983). These findings are consistent with Yantis and Jonides's (1984; see also Jonides \& Yantis, 1988; Yantis \& Jonides, 1990) claim that sudden onsets can automatically "capture attention" and have led to two hypotheses as to how simultaneous onsets may delay focal attending to the target.

Van der Heijden (1992, p. 267) has suggested that when multiple display elements have simultaneous onsets, attention may be captured by a single onset element before it has been fully identified. This model assumes that if the element that initially captures attention is the target, attention will remain at this target location; whereas if attention is initially captured by a noise element, attention will subsequently withdraw and move to the target. Increasing the number of noise elements will increase the probability that a noise element will be attended before the target. Thus, on average, target responses will be slower and less accurate for displays containing more noise elements than will target responses for displays containing fewer noise elements. This conception of attentional capture will be referred to as the single capture model.

Another possible explanation is that multiple elements that appear simultaneously together are initially perceived as a single object due to the Gestalt perceptual principle of common fate. Thus, all elements may si- 
multaneously capture attention. Unlike the single capture model, this simultaneous capture model assumes that the distraction effect is dependent on perceptual grouping among target and noise, and not on the number of noise elements present. For example, if target and noise appear simultaneously and are arranged in a circular array, this display may be initially perceived holistically as a circle. The distraction effect could then be due to initial difficulty in segregating a single target element from the perceived circle of elements (see also Neisser, 1967, and Watt, 1988). This segregation process may take time, and time to segregate may depend on other grouping properties, such as spatial separation of target and noise, target-noise feature similarity, or noise-noise feature similarity (Duncan \& Humphreys, 1989). Increasing target-noise grouping is assumed to increase the distraction effect by increasing the time necessary to segregate the target from noise.

In sum, there has been much indirect evidence that the distraction effect may be due to delays in focally attending to a target. However, the response competition explanation of the distraction effect proposed by Grice and Canham (1990) can just as easily account for the above findings. A more direct method of testing whether noise delays focal attending to a target was performed in Experiment 1. Basically, the results of Experiment 1 reveal that the distraction effect is indeed due to delays in selective attention, and not to response competition. In addition, the results of Experiment 2 show that delays in attending are not dependent on the number of noise elements, but on target-noise grouping by proximity. Finally, the results of Experiment 3 show that these attention delays are not simply due to delays in locating the target, but are also due to delays in perceptually segregating the target from noise. Experimental evidence best supports perceptual segregation as assumed by the simultaneous capture model in explaining attention delays when the goal is to attend and respond to a single object among simultaneously presented visual elements.

\section{EXPERIMENT 1}

The C. W. Eriksen, Webb, and Fournier (1990) methodology (in their Experiment 3) provides estimations of how long a stimulus can be visually presented before receiving focal attention. This methodology will be used to examine whether noise presented along with a target causes delays in shifting attention to (or focusing attention on) the target and whether these attention delays increase with increases in the number of noise elements. Attention was directed to one stimulus in a visual display containing one, four, or eight letters by cuing a single stimulus location (target location) either before (precue) or simultaneously with display onset. Subjects were required to discriminate which of two targets were present in the cued location. At different time delays after display onset, the identity of the cued stimulus sometimes changed; a noise letter changed to a tar- get $(\mathrm{N}-\mathrm{T})$, a target changed to the alternative target (T1-T2), or the identity of the target initially appearing in the cued location did not change (no-change control).

If selection and processing of the stimulus in the cued location begins before the original stimulus changes to the new stimulus (actual target), RT to the new target in both the $\mathrm{N}-\mathrm{T}$ and the $\mathrm{T} 1-\mathrm{T} 2$ conditions should increase relative to RT to the no-change control (C. W. Eriksen et al., 1990). This is because selection of the new target would have to start fresh once the original stimulus changes to the new target in the $\mathrm{N}-\mathrm{T}$ and $\mathrm{T} 1-\mathrm{T} 2$ conditions. If, however, the original stimulus in the $\mathrm{N}-\mathrm{T}$ and $\mathrm{T} 1-\mathrm{T} 2$ conditions does not receive attentional selection and processing before its identity changes, then RT and accuracy to the new target should be no different than that in the no-change control.

It is predicted that when more noise elements are present in the display, delays in attending to the cued stimulus location will be longer than when fewer or no noise elements are present. In other words, the original stimulus in the $\mathrm{N}-\mathrm{T}$ and $\mathrm{T} 1-\mathrm{T} 2$ conditions may be presented at longer time intervals (change delays) without being attended when more, as opposed to fewer, noise elements are present. Thus, RTs and errors in the N-T and $\mathrm{T} 1-\mathrm{T} 2$ conditions should be greater than those in the nochange control condition at earlier letter change delays when fewer or no noise elements are present.

It is also predicted that precuing the target location will give attention a head start in shifting to the cued location, which will decrease delays in attending to the cued stimulus. In other words, the original stimulus in the $\mathrm{N}-\mathrm{T}$ and $\mathrm{T} 1-\mathrm{T} 2$ conditions should begin to be attended and interfere with discrimination performance to the new target at earlier change delays when the target location is precued, as opposed to simultaneously cued (C. W. Eriksen et al., 1990). Thus, RTs and errors in the $\mathrm{N}-\mathrm{T}$ and $\mathrm{T} 1-\mathrm{T} 2$ conditions should be greater than those in the no-change control condition at earlier change delays when the target location is precued.

Following from the findings and interpretations of C. W. Eriksen et al. (1990), increases in RT and errors (and possibly RT and error increases at shorter change delays) are expected to be greater in the T1-T2 condition than those in the $\mathrm{N}-\mathrm{T}$ condition. Attending to $\mathrm{T} 1$ can cause response priming (response competition) that will need to be overridden in order to respond correctly to $\mathrm{T} 2$. Overriding response priming by $\mathrm{T} 1$ in order to respond to T2 will take time (C. W. Eriksen et al., 1990). In the $\mathrm{N}-\mathrm{T}$ condition, the noise element does not prime a response and will not require extra time to override response priming in order to respond to the target once it finally appears.

\section{Method}

Subjects. The subjects were graduate and undergraduate students from the University of Illinois at Urbana-Champaign who served as paid volunteers. All subjects were right-handed and had normal or corrected-to-normal vision, which was assessed by questioning. Six men and 5 women participated in Experiment 1. 
Apparatus and Stimuli. Letter stimuli were presented on a CRT at a distance of $114 \mathrm{~cm}$ and a luminance of $26.04 \mathrm{~cd} / \mathrm{m}^{2}$ as measured by a Spectra Brightness Spotmeter. Letters were in uppercase, colored white, and were $0.25^{\circ}$ high. Targets were $\mathrm{A}$ and $\mathrm{N}$. Noise letters requiring no response were $\mathrm{M}, \mathrm{E}$, and $\mathrm{K}$. The target and noise letters were chosen to be highly confusable at brief presentations in order to require focal attending to the target (Fournier \& C. W. Eriksen, 1990; Treisman \& Gelade, 1980). A white fixation cross measuring $0.10^{\circ}$ appeared in the center of the screen before and during each trial. The subjects viewed stimuli binocularly through a face mask.

The number of letters present in a display varied randomly within each block. Letter displays were centered around a fixation cross and consisted of (1) a single letter occupying one of eight possible equally spaced clock positions, (2) four letters appearing at $12,3,6$, and 9 o'clock positions, or (3) eight letters equally spaced presented in a circular array. The center of the letters in all displays were approximately $1.3^{\circ}$ from the fixation cross.

One letter position in each display was cued by white dashes, centered to the right and left of the letter. Each dash was $0.15^{\circ}$ in length and $0.20^{\circ}$ from the edge of the letter. This cue indicated the target location. Cues appeared either simultaneously with or $50 \mathrm{msec}$ before letter onset. Letter displays appeared for $200 \mathrm{msec}$.

A hand button held in the left hand was used to initiate trials, and a hand lever held in the right hand was moved to the right or left to indicate which target appeared in the cued location. The computer recorded response direction, RT, and accuracy.

Procedure. The subjects were instructed to be sure that the fixation cross was in clear focus and to fixate their eyes on this cross throughout the trial in order to locate the cue efficiently. One second after pressing the hand button, a one-, four-, or eight-letter display appeared. In all displays, one letter position was cued; a target would always occupy this cued position. Half of the subjects moved the hand lever to the right for the target $A$ and to the left for the target $\mathrm{N}$, and the other half of the subjects moved the lever to the left for the target $\mathrm{A}$ and to the right for the target $\mathrm{N}$. The target never appeared outside the cued location, and noncued letters were to be ignored. The subjects were instructed to respond quickly and accurately. Following each trial, the computer displayed RT and accuracy of response.

At 17,33 , or 83 msec after letter onset, the letter in the cued location could change. There were three types of letter change conditions: the N-T condition in which the noise letter initially appearing in the cued position was changed to a target (e.g., $\mathrm{K}$ changed to A), the T1-T2 condition in which the target initially appearing in the cued position was changed to the other target (e.g., A changed to $\mathrm{N}$ ), and the no-change control condition in which the target initially appearing in the cued position did not change. ${ }^{3}$ (See Figure 1.)

Because subjects in the T1-T2 condition could possibly perceive and respond to the target initially occupying the cued location (T1) before it changed to the new target (T2) as well as respond to the new target (T2), they received feedback that they were correct regardless of their response in this condition. This feedback was given because, technically, the subjects were correct whether they responded to T1 or T2. However, only trials in which the subjects responded correctly to the new target (T2) were scored as correct for data analysis purposes (see also C. W. Eriksen et al., 1990). ${ }^{4}$ The subjects were not told that the letters in the cued location could change.

Each block of 54 trials consisted of 18 one-letter, 18 four-letter, and 18 eight-letter displays presented in random order. A target appeared at least twice in each location in both the eight-letter and the one-letter displays and at least four times in each of the fourletter display locations. The targets that appeared an extra time in two possible letter locations in the three different display sizes were approximately evenly distributed among the possible letter locations within and between blocks. Each display size contained

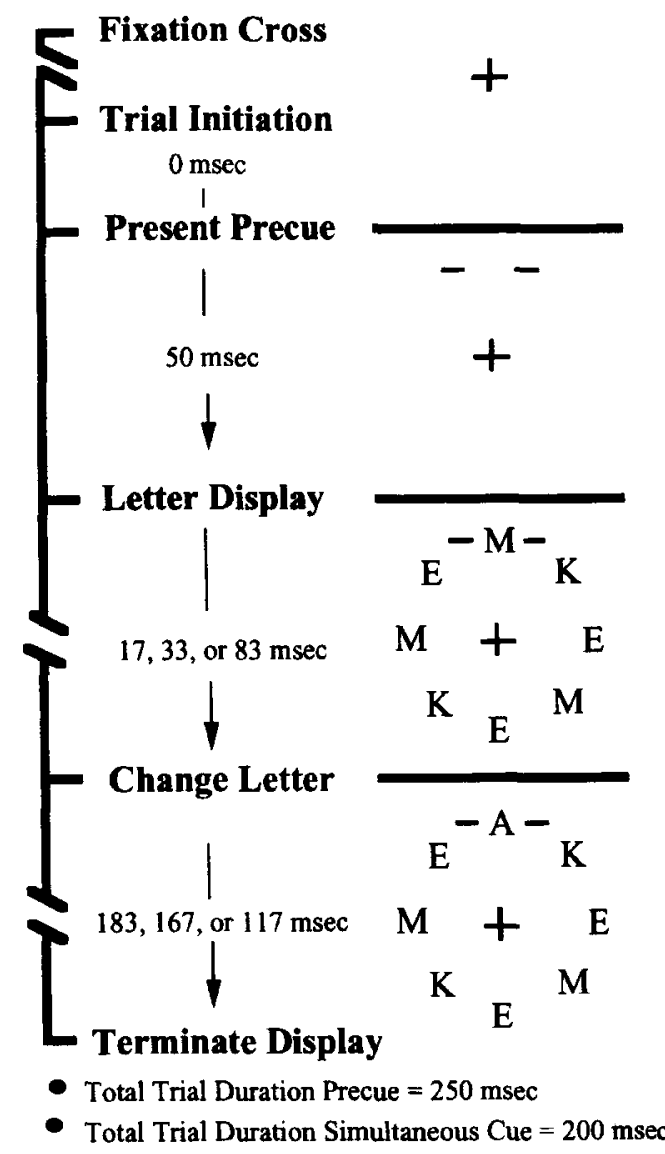

Figure 1. Example of stimulation sequence of events in Experiment 1.

an equal number of trials of the three letter change conditions (N-T, T1-T2, and no-change control) at each of the three different change delays $(17,33$, and $83 \mathrm{msec})$ within a block. In the T1-T2 condition, each possible target that initially appeared in the cued location ( $\mathrm{T} 1$ ) was presented at all three change delays equally within a block; in the N-T condition, each possible noise letter that appeared initially in the cued location was presented at all three change delays approximately equally across blocks. Also, the target letter replacing the original stimulus appeared equally often in each display size within each letter change condition at each of the change delays. Noise letters that were not cued appeared randomly in the four-letter and eight-letter displays such that no two identical noise letters appeared next to one another.

The subjects completed three 1-h sessions over 2 to 3 days. Each session consisted of 10 blocks of 54 trials each. Five blocks contained precued displays and 5 blocks contained simultaneous cued displays. A precued display block was always followed by a simultaneous cued display block (and vice versa) within subjects, and order of cue block presentation was counterbalanced across subjects. The first session was considered practice and was not included in data analyses.

\section{Results and Discussion}

A four-way within-subject analysis of variance (ANOVA), with cue type $(2) \times$ display size $(3) \times$ letter change (3) $\times$ change delay (3), was performed on mean correct RTs and percent errors. Mean correct RTs and percent errors for the three display sizes with both types 
Table 1

Mean Correct Reaction Times (in Milliseconds) for the Three Display Sizes at the Three Change Delays (in Milliseconds) Within Each Cue Condition in Experiment 1

\begin{tabular}{|c|c|c|c|c|c|c|c|c|c|}
\hline \multirow[b]{2}{*}{ Change Delay } & \multicolumn{3}{|c|}{ One Letter } & \multicolumn{3}{|c|}{ Four Letters } & \multicolumn{3}{|c|}{ Eight Letters } \\
\hline & Control & $\mathrm{N}-\mathrm{T}$ & $\mathrm{T} 1-\mathrm{T} 2$ & Control & $\mathrm{N}-\mathrm{T}$ & $\mathrm{T} 1-\mathrm{T} 2$ & Control & $\mathrm{N}-\mathrm{T}$ & $\mathrm{T} 1-\overline{\mathrm{T} 2}$ \\
\hline \multicolumn{10}{|c|}{ Simultaneous Cued Displays } \\
\hline 17 & 489 & 487 & 502 & 510 & 521 & 535 & 520 & 535 & 532 \\
\hline 33 & 489 & $507^{*}$ & $516^{*}$ & 523 & 519 & 534 & 540 & 543 & 534 \\
\hline 83 & 487 & $538^{*}$ & $572 \dagger$ & 522 & $552^{*}$ & $572 \dagger$ & 542 & 551 & $559^{*}$ \\
\hline \multicolumn{10}{|c|}{ Precued Displays } \\
\hline 17 & 457 & 462 & $487 \dagger$ & 478 & 487 & 472 & 498 & 493 & 501 \\
\hline 33 & 469 & $491^{*}$ & $514 \dagger$ & 481 & 494 & $506^{*}$ & 494 & 504 & $525 \dagger$ \\
\hline 83 & 469 & $522^{*}$ & $572 \dagger$ & 481 & $529^{*}$ & $553 \dagger$ & 496 & $525^{*}$ & $563 \dagger$ \\
\hline
\end{tabular}

* Mean reaction time greater than control condition $(p<.05)$, by planned comparison. †Mean reaction time greater than $\mathrm{N}-\mathrm{T}$ condition $(p<.05)$, by planned comparison.

Table 2

Percent Errors for the Three Display Sizes at the Three Change Delays (in Milliseconds) Within Each Cue Condition in Experiment 1

\begin{tabular}{|c|c|c|c|c|c|c|c|c|c|}
\hline \multirow[b]{2}{*}{ Change Delay } & \multicolumn{3}{|c|}{ One Letter } & \multicolumn{3}{|c|}{ Four Letters } & \multicolumn{3}{|c|}{ Eight Letters } \\
\hline & Control & $\mathrm{N}-\mathrm{T}$ & $\mathrm{T} 1-\mathrm{T} 2$ & Control & $\mathrm{N}-\mathrm{T}$ & $\mathrm{T} 1-\mathrm{T} 2$ & Control & $\mathrm{N}-\mathrm{T}$ & $\mathrm{T} 1-\mathrm{T} 2$ \\
\hline \multicolumn{10}{|c|}{ Simultaneous Cued Displays } \\
\hline 17 & 6.4 & 8.6 & 9.5 & 15.5 & 17.3 & 15.0 & 15.0 & 24.1 & 14.1 \\
\hline 33 & 4.5 & 7.3 & 6.8 & 16.8 & 15.5 & 20.0 & 15.5 & 20.9 & 25.0 \\
\hline 83 & 7.2 & 19.1 & 36.8 & 17.3 & 23.6 & 41.0 & 14.1 & 14.1 & 34.5 \\
\hline \multicolumn{10}{|c|}{ Precued Displays } \\
\hline 17 & 5.0 & 5.5 & 11.4 & 10.5 & 24.1 & 15.9 & 14.1 & 13.6 & 21.9 \\
\hline 33 & 6.4 & 13.2 & 17.3 & 13.6 & 18.6 & 19.5 & 12.7 & 15.9 & 21.8 \\
\hline 83 & 4.1 & 21.4 & 50.9 & 10.0 & 26.8 & 46.4 & 13.6 & 20.9 & 38.6 \\
\hline
\end{tabular}

of cuing and the three types of letter changes at the three change delays are shown in Tables 1 and 2 , respectively.

Reaction time. All main effects and interactions were significant $(p<.05)$ except for the cue type $\times$ change delay interaction $[F(2,20)=2.9, p=.08]$ and the display size $\times$ letter change $\times$ change delay interaction $[F(8,80)$ $=1.8, p=.09$ ], which were marginally significant, and the three-way interaction of cue type $X$ display size $\times$ change delay $[F(4,40)=0.64, p>.50]$ and the four-way interaction of cue type $\times$ display size $\times$ letter change $\times$ change delay $[F(8,80)=.86, p>.50]$, which were not significant.

The major concern in Experiment 1 centered on the changing of the stimulus after the subject had had the opportunity to preview the display for 17,33 , or $83 \mathrm{msec}$. Similar to the findings of C. W. Eriksen et al. (1990), RTs in the N-T and T1-T2 conditions increased relative to the no-change control as the letter change delay duration increased, while RTs in the no-change control condition did not differ across letter change delays [letter change $\times$ change delay, $F(4,40)=24.48, p<$ .01]. (See Table 1.) This finding suggests that the longer the original stimulus was previewed in the $\mathrm{N}-\mathrm{T}$ and $\mathrm{T} 1-\mathrm{T} 2$ conditions, the more likely this original stimulus was to be processed and to interfere with response to the new target, which inflated RTs relative to those in the no-change control condition.
As predicted, it appears that the original stimulus in the N-T and T1-T2 conditions was more likely to be processed before its identity changed at shorter change delays when fewer noise elements, as opposed to more noise elements, were present. Mean RTs in the N-T and $\mathrm{T} 1-\mathrm{T} 2$ conditions were longer relative to mean $\mathrm{RT}$ in the no-change control condition when fewer (or no) noise elements were present [display size $\times$ letter change, $F(4,40)=8.61, p<.01]$. Also, the longer RTs in the N-T and T1-T2 conditions, relative to the RTs in the nochange control condition, occurred at earlier change delays when fewer (or no) noise elements were present [display size $\times$ change delay, $F(4,40)=2.76, p<.05$ ] These findings show that when fewer (or no) noise elements are present, the cued stimulus can be selected and processed sooner than when more elements are present.

In addition, $\mathrm{RTs}$ in the $\mathrm{N}-\mathrm{T}$ and $\mathrm{T} 1-\mathrm{T} 2$ conditions were longer, relative to RTs in the no-change control condition, at shorter change delays when the target was precued as opposed to when the target was simultaneously cued [cue type $\times$ letter change $\times$ change delay, $F(4,40)=5.16, p<.001]$. Furthermore, RTs in the $\mathrm{N}-\mathrm{T}$ and $\mathrm{T} 1-\mathrm{T} 2$ conditions were longer, relative to $\mathrm{RTs}$ in the no-change control condition, when the precued target appeared among fewer noise elements (cue type $\times$ display size $\times$ letter change, $F(4,40)=3.14, p<.05$ ]. In the simultaneous cued displays, the longest change delay in 
which RTs were no different from those in the no-change control condition in the eight-, four-, and one-letter displays were 83,33 , and $17 \mathrm{msec}$, respectively, for the $\mathrm{N}-\mathrm{T}$ condition, and 33,33 , and $17 \mathrm{msec}$, respectively, for the T1-T2 condition. In the precued displays, the longest change delay in which RTs were no different from those in the no-change control condition was $33 \mathrm{msec}$ for the N-T and $17 \mathrm{msec}$ for the T1-T2 condition in both the eight- and four-letter displays, and $17 \mathrm{msec}$ for the N-T and less than $17 \mathrm{msec}$ for the T1T2 condition in the one-letter displays. (See Table 1.) ${ }^{5}$ These findings show that stimulus selection and processing at the cued location begins earlier when this location is precued and when fewer noise elements are contained in the display.

As indicated in Table 1, the T1-T2 condition sometimes showed significantly greater increases in RT than did the N-T condition, and it sometimes showed significant RT increases relative to the no-change control at shorter change delays than did the $\mathrm{N}-\mathrm{T}$ condition. These results are consistent with those found by $\mathrm{C}$. W. Eriksen et al. (1990) and are attributed to response priming interference in the T1-T2 condition and the lack of such interference in the $\mathrm{N}-\mathrm{T}$ condition.

Errors. Error data trends were consistent with the results and interpretations of the correct RT data and are not indicative of any speed-accuracy tradeoff (see Table 2). Increases in errors were found at earlier change delays in the $\mathrm{N}-\mathrm{T}$ and $\mathrm{T} 1-\mathrm{T} 2$ conditions than in the nochange control condition when fewer or no noise elements were present [display size $\times$ letter change $X$ change delay, $F(8,80)=2.76, p<.01]$. This finding again suggests that the original stimulus in the $\mathrm{N}-\mathrm{T}$ and $\mathrm{T} 1-\mathrm{T} 2$ conditions was processed more often and at earlier change delays when fewer noise elements were present in the display. Increased errors in the T1-T2 condition are thought to be due to the increased probability that the original stimulus (T1) was responded to (which would be counted as an error) instead of the new stimulus (T2). In addition, increased errors in the N-T condition might have been due to increased probability that responses were based on some guesses when the original noise stimulus was selected and processed.

When the target location was precued, errors decreased in the letter change control condition and increased in both the $\mathrm{N}-\mathrm{T}$ and the $\mathrm{T} 1-\mathrm{T} 2$ conditions across the one-, four-, and eight-letter displays relative to when the target location was simultaneously cued [cue type $\times$ letter change, $F(2,20)=4.0, p<.05]$. This finding suggests that precuing allowed the cued stimulus to be selected and processed earlier (before the original stimulus changed to the new target) and resulted in more errors in the $\mathrm{N}-\mathrm{T}$ and $\mathrm{T} 1-\mathrm{T} 2$ conditions than in the no-change control condition. Moreover, precuing the target location led to significantly more errors in the $\mathrm{N}-\mathrm{T}$ and T1-T2 conditions than in the no-change control condition when fewer noise elements were present [cue type $\times$ display size $\times$ letter change, $F(4,40)=4.60, p<$
.01]. Consistent with the correct RT results, these findings suggest that the original stimulus in the cued location was attended and processed more often when the target location was precued and when fewer noise elements were present.

Taken together, these findings demonstrate that the number of noise elements present in the display influences how long a stimulus can be previewed before it receives focal attention. It is assumed that subjects must first detect the location cue and then shift focal attention to the cued location in order for the cued stimulus to receive processing in the conscious system. Some measurable amount of time is required to direct attention to this cued location (see C. W. Eriksen et al., 1990; C. W. Eriksen \& Yeh, 1985). Increasing the number of noise elements appears to delay attentional selection and processing of a cued stimulus. Response interference in the $\mathrm{N}-\mathrm{T}$ and $\mathrm{T} 1-\mathrm{T} 2$ conditions was shown to decrease with increases in noise. In addition, providing stimulus location information $50 \mathrm{msec}$ before the stimulus presentation allowed this cued stimulus to be selected earlier. Also, response interference in the $\mathrm{N}-\mathrm{T}$ and $\mathrm{T} 1-\mathrm{T} 2$ conditions was shown to increase more when precued than when simultaneously cued. It is estimated from both the RT data and the error data in the N-T and T1-T2 conditions that the minimum amount of time that the subjects were able to direct focal attention to the cued stimulus ranged from 83 to $133 \mathrm{msec}, 67$ to $83 \mathrm{msec}$, and 17 to $33 \mathrm{msec}$ in the eight-, four-, and one-letter displays, respectively. The earliest interference from the letter initially appearing in the cue location occurred between these change delays.

The above findings are not consistent with a response competition explanation of the distraction effect (Grice \& Canham, 1990). These results suggest instead that increases in target discrimination RT with increases in the number of noise elements is due to slower attention selection of the target. Processing the original stimulus in the $\mathrm{N}-\mathrm{T}$ and $\mathrm{T} 1-\mathrm{T} 2$ conditions was shown to be delayed when the number of noise elements in the display increased. The question now becomes "Why is attention selection slower?"

One possibility is that attentional selection is delayed due to random attentional capture by a single noise element. Another possibility is that simultaneous items are seen initially as a single object that captures attention, and time is needed to segregate as well as locate the target among noise. Both concepts are compatible with the estimates of attention shift times in Experiment 1. However, if the spatial grouping of target and noise stimuli can be shown to be a more important variable in the distraction effect than the number of noise stimuli simultaneously presented with the target, the single capture model would be weakened and the simultaneous capture model would be strengthened.

Both capture models assume that delays in attending to a relevant stimulus are due to difficulties in focusing attention on the relevant stimulus location (Kahneman 
et al., 1983). Precuing the relevant stimulus location by $50 \mathrm{msec}$ reduced, but did not eliminate, the distraction effect in the no-change control condition in Experiment 1 . Within the no-change control condition, RTs to the precued four-letter displays $(M=480 \mathrm{msec})$ and eight-letter displays $(M=496 \mathrm{msec})$ were significantly slower than RTs to the precued one-letter displays $(M=$ $465 \mathrm{msec})$ by planned comparisons $(p<.01)$. Perhaps the 50 -msec precue did not allow sufficient time for attention to shift to (or focus on) the cued location on each trial before display onset. If the target location was precued earlier, attention might have sufficient time to shift to the target location before display onset on each trial and eliminate the distraction effect.

It is difficult to determine whether longer selection delays as display size increased in Experiment 1 are due simply to an increase in the number of noise elements or to increased target-noise proximity. The spatial distance between the cued stimulus and noise decreased as the number of noise elements increased. Letters were separated by approximately $1.65^{\circ}$ in the four-letter displays and $0.80^{\circ}$ in the eight-letter displays. Perhaps the cue, cued stimulus, or both were more difficult to detect due to increased lateral interference in the eight-letter displays (Estes, 1972).

Also, eight possible target locations were used in the one- and eight-letter displays, but only four were used in the four-letter displays $(12,3,6$, and 9 o'clock). Thus, comparisons between the four- and eight-letter displays are confounded by differences in target location probability. This confound was eliminated in Experiment 2 and was shown not to compromise the above interpretations.

\section{EXPERIMENT 2}

The purpose of Experiment 2 was threefold. First, it examined whether attentional delays (as display size increased) in Experiment 1 were partly due to the differences in the ability to perceive and locate the cue. Second, it examined whether attentional delays can be eliminated if attention has sufficient time to focus on the target location before onset of the display. Finally, it examined whether attentional delays are dependent on the number of noise elements, as the single capture model suggests, or whether attention delays are better explained by difficulties in segregating the target from noise, as suggested by the simultaneous capture model.

Stimulus displays consisted of one, two, four, and eight letters. Target-noise separation varied in the twoand four-letter displays and was constant in the eight-letter displays. Target location was indicated by a red or white cue at various precue-target stimulus onset asynchronies (SOAs). It was thought that the red cue may be more salient than the white cue, since the letters in the display were all white. Subjects discriminated which of two targets appeared in the cued location.

If cue detection was worse in the eight-letter displays in Experiment 1, then target discrimination RTs in the eight-letter displays and displays containing similar target- noise spacing should benefit more from the red cue (over the white cue), relative to displays containing noise spaced farther from the target. In addition, if the distraction effect can be eliminated when attention has sufficient time to focus on the target location before display onset, there should be no difference in RTs across the different displays when the target location is precued well before the display $(200 \mathrm{msec})$. Finally, if increasing the number of noise elements in the display increases the probability that one or more noise elements will capture attention before the target, then displays containing fewer noise elements with target-noise separations equivalent to that of the eight-letter displays should have faster target RTs than the eight-letter displays.

\section{Method}

Subjects. The subjects were graduate and undergraduate students from the University of Illinois at Urbana-Champaign who served as paid volunteers. All subjects were right-handed and had normal or corrected-to-normal vision, which was assessed by questioning. Six men and 8 women participated in Experiment 2 .

Apparatus and Stimuli. Apparatus, letter stimuli, and the cue indicator were identical to those used in Experiment 1 with the following exceptions. The noise letter $M$ was replaced by the letter W. ${ }^{6}$ The cued letter never changed its identity and was always the target $\mathrm{A}$ or $\mathrm{N}$. The cue indicator was colored red or white, and the letter stimuli were colored white.

Letter displays consisted of either one, two, four, or eight letters. The center of the letters in all display size sets appeared $1.37^{\circ}$ from the fixation cross. Letters were separated by $0.82^{\circ}$ in the eight-letter displays. There were four different letter configurations in both the two- and four-letter displays (see Figure 2). In the two-letter displays, the target and noise letter were separated by (1) adjacent positions $\left(0.82^{\circ}\right)$, (2) one letter position $\left(1.78^{\circ}\right)$, (3) two letter positions $\left(2.25^{\circ}\right)$, or (4) three letter positions $\left(2.60^{\circ}\right)$. In the four-letter displays, target and noise were separated by (1) one letter position ( $1.78^{\circ}$ noise-target separation), while the remaining noise letter was diametrically opposite to the target $\left(2.60^{\circ}\right.$ from the target), (2) an adjacent letter position and two letter positions $\left(0.82^{\circ}\right.$ and $2.25^{\circ}$ noise-target separation), while the remaining noise letter was diametrically opposite the target, (3) adjacent letter positions $\left(0.82^{\circ}\right.$ target-noise separation), while the remaining noise letter was diametrically opposite to the target, or (4) adjacent letter locations $\left(0.82^{\circ}\right.$ target-noise separation), while the remaining noise letter appeared adjacent to a noise letter $\left(1.78^{\circ}\right.$ from the target). The target letter in each letter display appeared in each of eight possible locations around the fixation cross.

Procedure. Experimental procedures and instructions were identical to those of Experiment 1 with the following exceptions. The subjects were told that they would see one-, two-, four-, and eight-letter displays. In all displays, one letter position was cued (with red or white dashes) and a target letter ( $\mathrm{A}$ or $\mathrm{N}$ ) always occupied this cued position. Before each trial, the subjects saw a small circle $0.10^{\circ}$ of visual angle in the center of the CRT. After approximately $1 \mathrm{sec}$, this circle was replaced by a fixation cross. The fixation cross was either white or red and corresponded to the color of the cue. Stimulus letters appeared for $50 \mathrm{msec}$. The target location cue appeared at SOAs of $0,50,150$, or $200 \mathrm{msec}$ before display onset and remained in view until display offset.

Each block of 64 trials consisted of 16 one-letter, 16 two-letter, 16 four-letter, and 16 eight-letter displays presented in random order. The variables of display size, spatial configuration in the two- and four-letter displays, and target location were balanced across both cue color and cue SOA. Cue color (red or white) was run on alternate blocks within each session, and order of cue color blocks (white or red cue first) were balanced within and between 


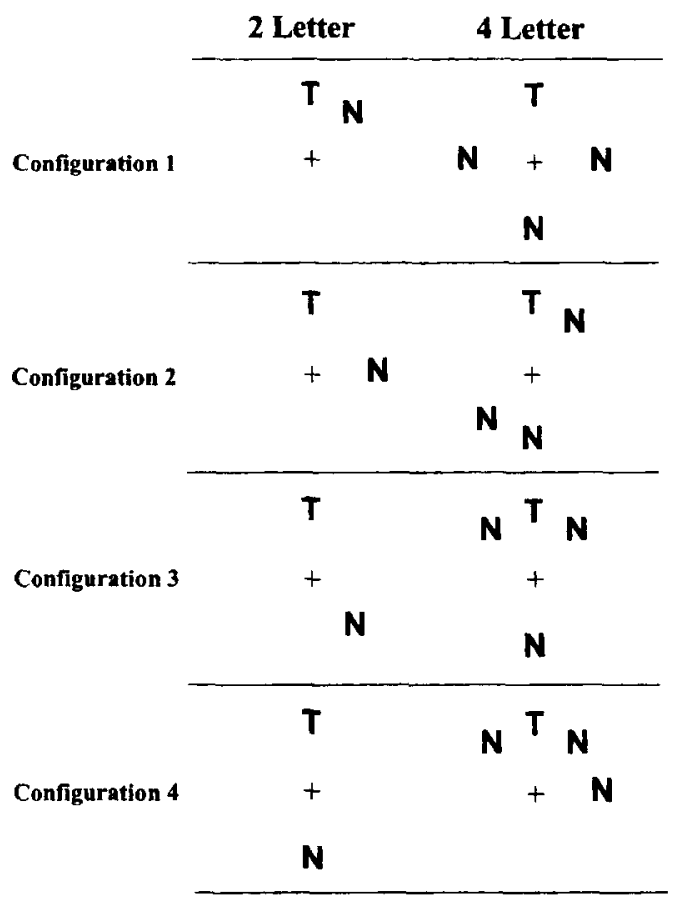

Figure 2. The four different letter configurations in the two-letter displays and four-letter displays in Experiment 2 and in the go/no-go response manipulation. $T$ represents a target letter ( $A$ or $N$ ); $N$ represents a noise letter (W, $E$, or $K)$. The target letter in each of the configurations could appear in any one of eight possible locations around the fixation cross.

subjects. Presentation order of cue SOA blocks were also counterbalanced across and within subjects.

The subjects completed five 1 -h sessions (one practice and four experimental sessions) over 5 to 10 days. Each session consisted of eight blocks of 64 trials. Data were analyzed for the experimental sessions only.

\section{Results and Discussion}

Two separate within-subject ANOVAs were carried out on correct target discrimination RTs and errors. ANOVA 1 (cue color [2] $\times$ cue SOA [4] $\times$ display size [4]) focused on display size, cue color, and cue SOA effects on RTs. ANOVA 2 (cue color [2] $\times$ cue SOA [4] $X$ display type [10]) was conducted to determine whether cue color, cue SOA, and the spatial configuration of noise independent of display size influence target RTs and errors; the one- and eight-letter displays as well as the four configurations in the two- and four-letter displays were considered to be different display types in this ANOVA. Mean correct RTs for each display size as a function of cue SOA collapsed over cue color are plotted in Figure 3, and percent errors are presented in Table 3.

Reaction times. A main effect of cue color was found [ANOVA $1, F(1,13)=33.09, p<.001$; and ANOVA 2, $F(1,13)=35.17, p<.0001]$. The red cue facilitated target RTs by 9 msec (relative to the white cue). However, there was no significant cue color $\times$ display size interaction [ANOVA 1, $F(3,39)=1.27, p>.25$ ] or cue color $\times$ display type interaction [ANOVA $2, F(9,117)=1.29$, $p=.25]$. These findings demonstrate that benefits in target discrimination when employing the red cue, as opposed to the white cue, were not dependent on target-noise proximity. This suggests that cue detection was equivalent across the different display sizes in Experiment 1 , and attention delays were not due to difficulties in cue detection. Because cue color did not interact with anything and did not influence accuracy, it will not be considered further.

Consistent with Experiment 1 and other research on the distraction effect, ANOVA 1 revealed that (1) increasing the number of noise elements caused target RTs to significantly increase [main effect of display size, $F(3,39)=59.58, p<.0001]$, (2) increasing the precue SOA caused target RTs to decrease [main effect of cue SOA, $F(3,39)=80.01, p<.0001]$, and (3) precuing benefited target discrimination more in displays containing more noise elements than in displays containing fewer noise elements [cue SOA $\times$ display size, $F(9,117)=$ $13.46, p<.0001]$. (See Figure 3.) The total benefit in target RTs for the one-, two-, four-, and eight-letter displays when precuing by $200 \mathrm{msec}$, relative to simultaneously cuing the target location, was $81,102,115$, and $128 \mathrm{msec}$, respectively.

As can be seen in Figure 3, precuing the target location by $150 \mathrm{msec}$ appears to have eliminated the distraction effect. Mean target RTs for one-letter displays ( $M=445 \mathrm{msec}$ ) appear no different than those for eightletter displays $(M=451 \mathrm{msec})$. Planned comparisons show no significant difference in target RTs among the four different display sizes or among the 10 display types $(p>.05)$. This result suggests that $150 \mathrm{msec}$ was sufficient time in the present experiment for focal attention to shift to (or focus on) the target location before display onset. Once focal attention is at the target location, elements outside of this cued location may not cap-

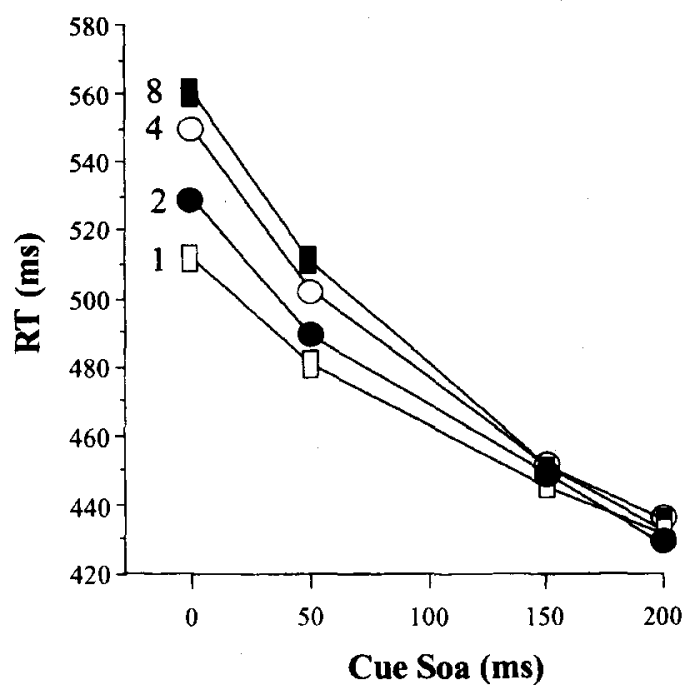

Figure 3. Mean correct target discrimination RT for each display size as a function of cue SOA in Experiment 2. 
Table 3

Percent Errors Within Each Display Configuration and Cue Stimulus Onset Asynchrony in Experiment 2

\begin{tabular}{ccccc}
\hline & \multicolumn{4}{c}{ Cue SOA (msec) } \\
\cline { 2 - 5 } Display & 0 & 50 & 150 & 200 \\
\hline One Letter & 4.0 & 3.6 & 4.9 & 4.2 \\
Two Letter & & & & \\
C1 & 12.0 & 5.1 & 3.4 & 3.4 \\
C2 & 7.1 & 5.8 & 3.6 & 3.8 \\
C3 & 8.9 & 4.2 & 3.8 & 3.8 \\
C4 & 7.6 & 3.8 & 3.4 & 2.7 \\
Four Letter & & & & \\
C1 & 10.5 & 5.1 & 3.8 & 5.8 \\
C2 & 11.6 & 7.4 & 3.8 & 4.7 \\
C3 & 11.2 & 5.1 & 6.9 & 4.5 \\
C4 & 12.3 & 8.9 & 6.7 & 6.0 \\
Eight Letter & 12.6 & 8.8 & 5.4 & 5.6 \\
\hline
\end{tabular}

Note $-\mathrm{C} 1-\mathrm{C} 4=$ Configurations $1-4$.

ture attention immediately (Yantis \& Jonides, 1990). This result also suggests that location information may facilitate target segregation from noise.

In order to determine whether the actual number of noise elements or the spatial grouping of target and noise are most responsible for the distraction effect, RT differences in displays that were simultaneously cued $(0-\mathrm{msec}$ cue SOA) were analyzed. As can be seen at the 0 -msec cue SOA in Figure 4, target RT appears to be influenced by both the number of noise and the spatial distance between the target and noise. Planned comparisons show that target RTs are fastest for the one-letter displays, followed by the two-letter display configurations, followed by Configurations 1 and 2 of the four-letter displays, followed by Configurations 3 and 4 of the fourletter displays and the eight-letter displays $(p<.05)$. However, when holding target-noise distance and retinal eccentricity constant, target RTs were shown to be no different. Mean target RTs in Configurations 3 and 4 of the four-letter displays ( $M=558$ and $554 \mathrm{msec}$, respectively) were not significantly different from RTs in the eightletter display $(M=561 \mathrm{msec})$ by planned comparisons $(p>.05)$. These findings suggest that the distraction effect depends more on target-noise proximity that on the actual number of noise elements in the display.

Errors. Error data were consistent with the above correct $\mathrm{RT}$ interpretations, and there was no suggestion of speed-accuracy tradeoffs. Percent errors ranged from $5 \%$ to $11 \%$ across subjects (see Table 3 ).

Consistent with the RT data, errors increased when more noise elements were present in the display [main effect of display size, $F(3,39)=37.03, p<.0001$ ], errors decreased as cue SOA increased [main effect of cue SOA, $F(3,39)=11.46, p<.0001]$, and the more noise elements in the display, the more errors were reduced by precuing (relative to simultaneously cuing) the target location [cue SOA $\times$ display size, $F(9,117)=9.55, p<$ $.0001]$. Moreover, errors were higher in displays containing noise elements close to the target, especially when noise elements were adjacent to the right and left of the target. At a cue SOA of $0 \mathrm{msec}$, planned comparisons showed no significant differences in errors when target-noise spacing was held constant across the different display size configurations; mean percent errors in the eight-letter displays ( $M=12.6 \%$ ) were not significantly different from Configuration $3(M=11.2 \%)$ and Configuration $4(M=12.3 \%)$ of the four-letter displays $(p>.05)$.

Mean RTs and errors were no different among the eight-letter displays and Configurations 3 and 4 of the four-letter displays; these display types also showed the highest RTs and percent errors, relative to the other display types. These results demonstrate that RTs are slowest and errors are highest when noise elements appear in adjacent locations $\left(0.82^{\circ}\right)$ to the right and left of the target, independent of the number of noise elements in the display. When the spatial separation of the closest noise elements surrounding the target are equated, it appears that disruption of target discrimination in displays containing only three noise elements can be equal to that in displays containing seven noise elements. Thus, delays in attending to the target in Experiment 1 are most likely due to the decreased spatial separation (or increased grouping) between the target and noise.

Similar results were found in a go/no-go task that was carried out using methods identical to those used in Experiment 2 (with the exception that subjects only responded if one of the targets was present). All significant effects were the same as in Experiment 2 except that there was no main effect of cue color. Although target detection times were approximately $120 \mathrm{msec}$ faster overall than the target discrimination times in Experiment 2, detection RT differences across the one-, two-, four-, and eight-letter displays when cuing the target location simultaneously with display onset were similar (see Figure 5). This finding demonstrates that the distraction effect, as well as response benefits from precuing, are not limited to choice RT tasks, as suggested by Grice and Canham (1990). Moreover, it suggests that distraction effects are due to perceptual variables, not response effects.

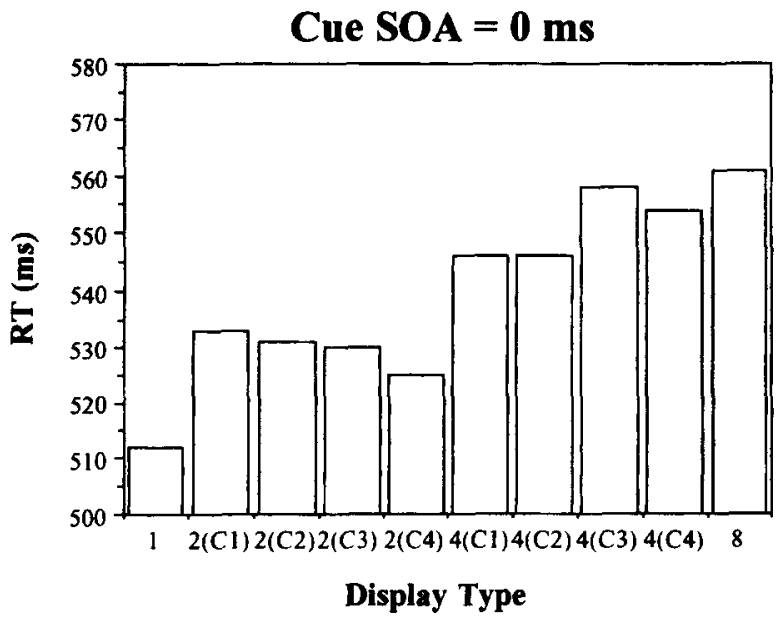

Figure 4. Mean correct target discrimination RTs for the 10 different display types at the 0-msec cue SOA in Experiment 2. 


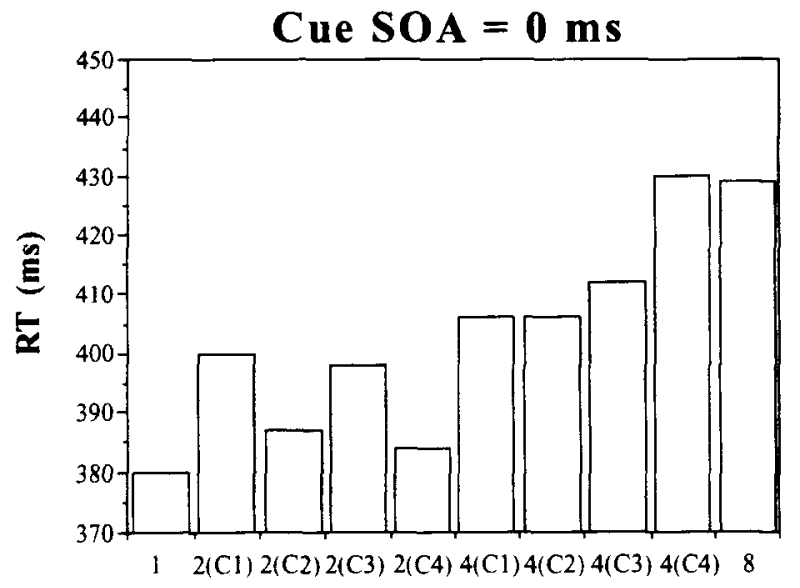

Display Type

Figure 5. Mean correct target detection RTs for the 10 different display types at the 0-msec cue SOA in the go/no-go response manipulation.

The above findings are not consistent with the single capture model, but are consistent with the simultaneous capture model. According to the latter model, delays in attending are dependent on time required to segregate the target from noise. It is assumed that increasing spatial proximity between target and noise will increase target segregation time independent of the number of noise elements present. Pan and C. W. Eriksen (1992) also provide evidence that distractions by noise are not due to single capture, but are dependent on spatial relationships among the targets and noise elements. The single capture model could account for the above findings by assuming that noise elements closer to the target have a higher probability of capturing attention on average than do noise elements farther removed. If this assumption were added, however, this model would still be unable to account for the findings of Banks and Prinzmetal (1976). They have shown that increasing the number of noise elements in the display in a visual search task (while holding target-noise proximity constant) can facilitate target detection if the added noise elements increase the degree to which the noise elements form perceptual groups separate from the target (see also Driver \& Baylis, 1989, Kahneman \& Chajzyck, 1983, Kahneman \& Henik, 1981, and Pan \& C. W. Eriksen, 1992). Thus, it appears that spatial organization can play an important role in determining selection times (see also Kramer \& Jacobson, 1991, and Treisman, Kahneman, \& Burkell,1983).

\section{EXPERIMENT 3}

If delays in attending are due to time needed to perceptually segregate the target among noise elements as well as to difficulties in locating and/or directing focal attention to this target (see Kahneman et al., 1983), then attentional delays should be dependent on target-noise feature similarity in nonsearch tasks. Target and noise elements that are featurally similar may tend to be grouped together, as opposed to target and noise elements that are featurally very different according to the Gestalt principle of similarity. Grunzke (1991) showed that target processing is delayed longer when noise elements share features with the target, relative to when noise elements do not, even though the target location was cued or precued $50 \mathrm{msec}$ before display onset. The method Grunzke employed was similar to that used in Experiment 1. Subjects discriminated which of two targets $(\mathrm{P}$ or $\mathrm{O})$ appeared in a cued location in a multielement display. Partial features of a target stimulus appeared initially in a cued location with display onset (e.g., the left vertical and top horizontal feature of the targets $O$ or $P$ ). At various change delays, these partial features were combined with features that would form a complete target. Results showed that the incomplete target could be presented at longer change delays before an increase in target RTs was observed when multiple noise elements in the display shared features with the target $(Q$ or $\mathrm{R})$, relative to when they $\operatorname{did} \operatorname{not}(\mathrm{X}$ or $\mathrm{Y})$.

Experiment 3 was designed to determine whether attentional delays in nonsearch tasks are dependent on target-noise feature similarity, as Grunzke's results suggest. Displays were similar to the eight-letter N-T displays and no-change control displays from Experiment 1 . Either one of two targets or a noise letter initially appeared in the cued or precued location. At different change delays, the noise letter initially appearing in the cued location changed to a target. Noise letters appearing in the noncued locations were either similar or dissimilar to the cued element.

It was predicted that target RTs and errors will be greater when noise elements in the noncued locations share features with the cued element (target or noise), relative to when they do not. In addition, target RTs and errors should increase for the $\mathrm{N}-\mathrm{T}$ condition, relative to the no-change control condition, at earlier change delays when noncued noise elements have dissimilar features to the cued element, as opposed to similar features. This is because segregation of the cued element should occur earlier when noise have dissimilar features to this cued element. This will lead to processing of the cued noise letter at earlier change delays and delay target discrimination. Finally, if precuing facilitates target noise segregation, then precuing should benefit target discrimination most in the no-change control condition when noise elements share similar features to the target, as opposed to dissimilar features. Also, precuing should lead to greater increases in target RT and errors in the N-T condition when noise features are dissimilar, as opposed to similar, to the target.

\section{Method}

Subjects. The subjects were graduate and undergraduate students from the University of Illinois at Urbana-Champaign who 
served as paid volunteers. All subjects were right-handed and had normal or corrected-to-normal vision, which was assessed by questioning. Four men and 4 women participated in Experiment 3.

Apparatus, Stimuli, and Procedure. Displays and procedures were similar to those used in the eight-letter $\mathrm{N}-\mathrm{T}$ conditions and no-change control conditions in Experiment 1 with the following exceptions. Either one of the target letters (A or N) or the noise letter $\mathrm{E}$, which shares features with the targets, initially appeared in the cued location. At change delays of $33,50,83$, or $100 \mathrm{msec}$, the noise letter $\mathrm{E}$ initially appearing in the cued location changed to the target $\mathrm{A}$ or $\mathrm{N}$. The target location was precued $50 \mathrm{msec}$ before or was cued simultaneously with letter display onset. Noncued noise letters had features either similar to the cued element (Hs or Ks) or dissimilar to the cued element (Ss or Cs).

The subjects determined whether the letter $\mathrm{A}$ or $\mathrm{N}$ appeared in the cued location. The target and noise letter appearing in the cued location, letter change conditions, letter change delays, and noncued noise letters (similar or dissimilar) occurred randomly and equally in each of the possible eight letter locations within a block. Cue type was run between blocks similar to Experiment 1. Each subject completed one practice and two experimental sessions consisting of eight blocks of 64 trials.

\section{Results and Discussion}

A within-subject ANOVA (cue type [2] $\times$ letter change [2] $\times$ noise similarity [2] $\times$ change delay [4]) was conducted on mean correct RTs and errors. Errors ranged from $3 \%$ to $12 \%$ across subjects, and error trends were not indicative of speed-accuracy tradeoffs. Mean RT and error data are presented in Figures 6 and 7.

Consistent with the results of Experiment 1, RT and errors were greater in the $\mathrm{N}-\mathrm{T}$ condition than in the nochange control condition [main effect of letter change, $F(1,7)=136.31, p<.001$, and $F(1,7)=14.02, p<.01$, for RTs and errors, respectively]. RTs were especially high in the $\mathrm{N}-\mathrm{T}$ condition at the longer change delays [letter change $\times$ change delay, $F(1,7)=30.99, p<.001$ ] (See Figure 6.) These findings suggest that the original noise letter in the cued location delayed selection of the target (in both similar and dissimilar noise displays), especially when this noise was presented at longer time intervals.

The main interest concerns whether the type of peripheral noise had an effect on target discrimination. Results showed that the noise similarity $X$ change delay and the noise similarity $\times$ letter change $\times$ change delay interactions were not significant $(p>.10)$. Overall, it appears that the change delays chosen were not sensitive enough to effectively estimate attention delay differences between noise sharing similar and noise sharing dissimilar features with the cued element.

However, target discrimination was slower and less accurate when noise elements were similar to the target [main effect of noise similarity, $F(1,7)=40.16, p<.001$, and $F(1,7)=7.64, p<.05$, for RTs and errors, respectively]. In addition, precuing led to overall faster RTs than did simultaneous cuing [main effect of cue type, $F(1,7)=51.69, p<.001]$. Precuing also reduced target RTs and errors in the no-change control condition more than that in the $\mathrm{N}-\mathrm{T}$ condition [cue type $\times$ letter change, $F(1,7)=29.75, p<.001$, and $F(1,7)=19.42, p<.01$, for RTs and errors, respectively]. (See Figure 7.) This sug-

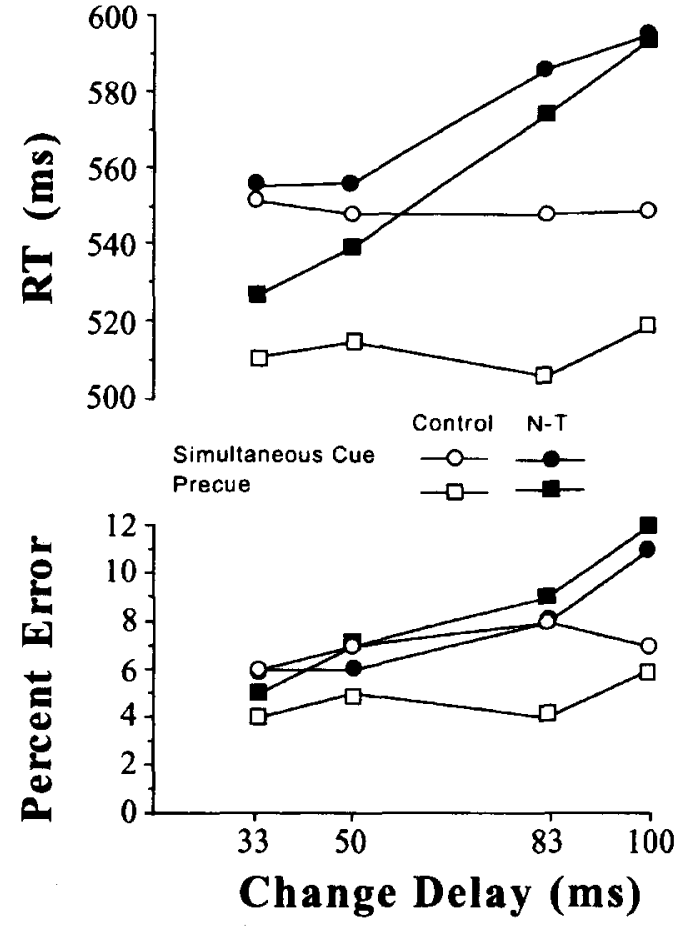

Figure 6. Mean correct target discrimination RTs and accuracy for the letter change conditions within each cue type across the four letter change delays in Experiment 3.

gests that precuing a stimulus location allowed earlier selection of the cued element than did simultaneous cuing. When the target originally appeared in the cued location, target selection was facilitated. However, when a noise letter originally occupied the cued location, target selection was hindered - especially when the noise letter appeared in the cued location at longer change delays [cue type $\times$ change delay interaction, $F(1,7)=6.41$, $p<.01$, for RTs]. Moreover, precuing benefited target RTs most when the noise in the display was similar, as opposed to dissimilar, to the target [cue type $\times$ noise similarity interaction, $F(1,7)=7.43, p<.05$ ], although target discrimination was slightly slower (approximately $6 \mathrm{msec}$ ) in the former case. (See Figure 7.) The simultaneously cued element appears to be initially more difficult to segregate when embedded among noise elements sharing features with the cued element since precuing benefits target RTs most in the no-change control condition when noise elements share features with the target.

These results are consistent with the perceptual segregation hypothesis. As predicted, precuing benefited target discrimination most in the no-change control condition when noise elements had features similar, as opposed to dissimilar, to the target. Precuing did not lead to much facilitation in the $\mathrm{N}-\mathrm{T}$ conditions for either noise condition, suggesting that precuing increased the probability that the noise element in the cued location disrupted target discrimination. It is assumed that precuing not only provides target location information but also facilitates target-noise segregation. Consistent with 

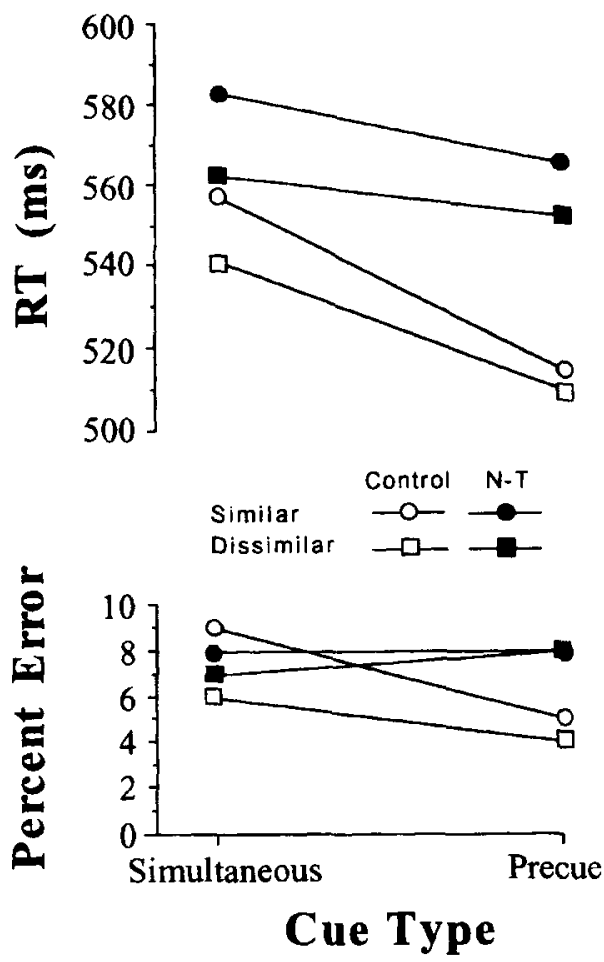

Figure 7. Mean correct target discrimination RTs and accuracy for similar and dissimilar noise conditions within each letter change condition across cue type in Experiment 3.

the interpretations and findings of the present results, C. W. Eriksen and Hoffman (1972b) showed that target RTs decreased with increases in precue SOA and RTs asymptoted at earlier precue SOAs when noise elements were dissimilar, as opposed to similar, to the target.

Although our change delays were apparently insufficient to allow us to measure how long attention was delayed when noise elements shared similar, as opposed to dissimilar, features with the target, the precue results suggest that attention is delayed longer when noise shares features with the target. Grunzke's findings and C. W. Eriksen and Hoffman's findings further support this idea.

\section{GENERAL DISCUSSION}

These experiments demonstrated that attention selection and processing of a single element is significantly delayed when it appears simultaneously with other irrelevant visual elements in nonsearch tasks. There was no evidence that distraction effects were due only to response competition, as suggested by Grice and Canham (1990). Processing of the original stimulus in the $\mathrm{N}-\mathrm{T}$ and $\mathrm{T} 1-\mathrm{T} 2$ conditions was shown to be delayed when noise elements were present. Second, attention delays were shown to depend on spatial separation between target and noise elements, and not on the number of noise elements. This finding is inconsistent with the assumptions of the single capture model but is consistent with the simultaneous capture model. Third, precuing a specific stimulus location was shown to reduce and eliminate delays in attending to the cued stimulus in both a two-choice discrimination task and a go/no-go detection task. Precuing can allow the relevant element to be located and segregated from the noise early enough to eliminate selection delays. Finally, delays in attending were shown to be longer when noise elements shared similar, as opposed to dissimilar, features with the target even though the target location was cued. Precuing facilitated selection more when noise shared features with the target, suggesting that precuing facilitates not only locating the target but segregating the target from the noise as well. Taken together, these findings suggest that all of the elements presented simultaneously in the display capture attention initially and simultaneously (as a whole), and delays in attending to a single relevant element are due to the time required to perceptually segregate the target from noise elements (this perceptual segregation idea is consistent with that proposed by Watt, 1988, pp. 127-129). Other Gestalt properties, such as proximity and feature similarity, were also shown to influence target segregation.

In order to ensure that the results of Experiments 1 and 2 were not due to increased difficulty in detecting the cue when noise elements were spatially closer to the cue, a cue detection experiment was conducted. Cue SOAs, cue colors, and the displays (one-letter, fourletter [Configurations 1 and 4], and eight-letter displays) from Experiment 2 were used. Cue detection was assessed by requiring subjects to detect whether a white or red cue was present or absent. Results showed that cue detection was overall faster for the red (vs. white) cue, but there was no evidence that cue detection was worse in displays containing more noise elements or noise elements spaced closer to the cue. In addition, there was no significant interaction between display type and cue SOA or display type and cue color. Moreover, there were no cue effects found in the go/no-go manipulation in Experiment 2. These findings together suggest that the cue was equally detectable among the different letter displays in Experiments 1 and 2.

The idea that a target element may need to be parsed from noise elements is often ignored in the attention literature. However, object-based theories of attention assume that limits on our ability to deal with several simultaneous visual events will depend on the number of objects that can be seen (Duncan, 1984). This is consistent with the idea that a target element may need to be parsed from noise elements. Unfortunately, the Gestalt grouping principle of common fate is rarely addressed in these models, even though most visual attention displays contain simultaneous onsets of target and noise elements.

Time required to segregate a single element among multiple elements will depend on the degree to which 
this element is perceptually embedded among other elements and will influence target detection and discrimination RTs (see Bundesen \& Pedersen, 1983; Driver \& Baylis, 1989; Kahneman \& Chajzyck, 1983; Kahneman \& Henik, 1981; Kramer \& Jacobson, 1991; Pomerantz \& Garner, 1973; Pomerantz \& Schwaitzberg, 1975; Treisman et al., 1983). Time to segregate a relevant element from irrelevant elements should increase and lead to longer target RTs when spatial separation of relevant and irrelevant elements is decreased, similarity between relevant and irrelevant elements is increased, similarity among irrelevant elements is decreased, time at which a relevant element precedes or follows onset of irrelevant elements is decreased, and the precue SOA of the relevant element is decreased. All of these manipulations increase target-noise grouping and have been shown to increase target detection and discrimination RTs, as discussed in the Introduction. Other examples include findings that display size effects are larger when target and noise share similar features (Duncan \& Humphreys, 1989; Treisman \& Gelade, 1980; Treisman \& Souther, 1985 ), and findings that a gradually unmasked target appearing simultaneously among gradually unmasked noise elements is discriminated slower than a target appearing suddenly among gradually unmasked noise elements (Jonides \& Yantis, 1988; Yantis \& Jonides, 1984; Yantis \& Jonides, 1990). It should be noted that one exception to this target-noise segregation requirement may occur if general feature pattern analysis of all elements is sufficient for stimulus detection responses.

There is also evidence suggesting that precuing a stimulus location may speed feature processing at this location (see C. W. Eriksen \& Murphy, 1987, and C. W. Eriksen \& Yeh, 1985, for a similar interpretation). In Experiments 1 and 2 (and in the go/no-go manipulation), precuing a single element (target) presented alone led to faster discrimination RTs than did simultaneously cuing this element. This result has been found in other studies as well, even though the precued target appeared at a constant location. These studies showed that precue benefits were not due to alerting effects or masking by the cue (C. W. Eriksen \& Hoffman, 1974; van der Heijden, Wolters, \& Enkeling, 1988). Perhaps speeded feature processing in the cued location allows the cued stimulus to be segregated from noise more quickly. This idea is consistent with the findings that precuing the target location by $200 \mathrm{msec}$ was sufficient to eliminate attention delays in the discrimination and detection tasks in Experiment 2.

Although precuing a target among neutral noise elements was shown to eliminate distraction effects in the present study, precuing a target among response-incompatible noise elements was found to reduce, but not eliminate, distraction effects (Colegate et al., 1973; C. W. Eriksen \& Hoffman, 1973; Hoffman, 1975). The latter finding can be explained as follows. Precuing may speed location and feature processing of the target (and, in turn, speed focal attending) and allow the target to finish processing before noise, but feature processing of both target and noise will always begin with display onset (van der Heijden \& Eerland, 1973; van der Heijden, Wolters, Groep, \& Hagenaar, 1987). Partial feature analysis of noise elements may be sufficient to prime responses before completion of target feature analysis (Coles, Gratton, Bashore, C. W. Eriksen, \& Donchin, 1985; Gratton, Coles, Sirevaag, C. W. Eriksen, \& Donchin, 1988). Thus, precuing may not be able to completely overcome response priming by noise elements.

In conclusion, because perception is known not to be instantaneous (C. W. Eriksen \& Collins, 1967; C. W. Eriksen \& Schultz, 1978), the initial perception of a stimulus may be that of a diffuse undifferentiated whole that subsequently becomes sharpened and differentiated over time (Flavell \& Draguns, 1957; Lockhead, 1979; Monahan \& Lockhead, 1977; Watt, 1988). Attention may be initially captured by this undifferentiated whole and may have to wait for perceptual processes to differentiate this whole into separate perceptual objects before attentional selection of one of these perceptual objects can take place.

\section{REFERENCES}

Banks, W. P., \& Prinzmetal, W. (1976). Configurational effects in visual information processing. Perception \& Psychophysics, 19, 361-367.

Bundesen, C., \& Pedersen, L. F. (1983). Color segregation and visual search. Perception \& Psychophysics, 33, 487-493.

Colegate, R. L., Hoffman, J. E., \& Eriksen, C. W. (1973). Selective encoding from multielement visual displays. Perception \& Psychophysics, 14, 217-224.

Coles, M. G. H., Gratton, G., Bashore, T. R., Eriksen, C. W., \& Donchin, E. (1985). A psychophysiological investigation of the continuous flow model of human information processing. Journal of Experimental Psychology: Human Perception \& Performance, 11, 529-553

Driver, J., \& Baylis, G. C. (1989). Movement and visual attention: The spotlight metaphor breaks down. Journal of Experimental Psychology: Human Perception \& Performance, 15, 448-456.

DunCan, J. (1984). Selective attention and the organization of visual information. Journal of Experimental Psychology: General, 113, 501-517.

DunCAN, J., \& Humphreys, G. W. (1989). Visual search and stimulus similarity. Psychological Review, 96, 433-458.

Egeth, H., Atkinson, J., Gilmore, G., \& Marcus, N. (1973). Factors affecting processing mode in visual search. Perception \& Psychophysics, 13, 394-402.

ERIKSEN, B. A., \& ERIKSEN, C. W. (1974). Effects of noise letters upon the identification of a target letter in a nonsearch task. Perception \& Psychophysics, 16, 143-149.

ERIKSEN, C. W., \& Collins, J. F. (1967). Some temporal characteristics of visual pattern perception. Journal of Experimental Psychology, 74, 476-484.

ERIKSEN, C. W., \& ERIKSEN, B. A. (1979). Target redundancy in visual search: Do repetitions of the target within the display impair processing? Perception \& Psychophysics, 26, 195-205.

Eriksen, C. W., Hamlin, R. M., \& Daye, C. (1973). The effect of flanking letters and digits on speed of identifying a letter. Bulletin of the Psychonomic Society, 2, 400-402.

ERIKSEN, C. W., \& Hoffman, J. E. (1972a). Some characteristics of selective attention in visual perception determined by vocal reaction time. Perception \& Psychophysics, 11, 169-171.

ERIKSEN, C. W., \& HofFMAN, J. E. (1972b). Temporal and spatial characteristics of selective encoding from visual displays. Perception \& Psychophysics, 12, 201-204.

ERIKSEN, C. W., \& HoffMan, J. E. (1973). The extent of processing of 
noise elements during selective encoding from visual displays. Perception \& Psychophysics, 14, 155-160.

Eriksen, C. W., \& Hoffman, J. E. (1974). Selective attention: Noise suppression or signal enhancement? Bulletin of the Psychonomic Society, 4, 587-589.

ERIKSEN, C. W., \& MURPHY, T. D. (1987). Temporal changes in the distribution of attention in the visual field in response to precues. Perception \& Psychophysics, 42, 576-586

Eriksen, C. W., \& Rohrbaugh, J. W. (1970). Some factors determining efficiency of selective attention. American Journal of Psychology, 83, 330-342.

ERIKSEN, C. W., \& Schultz, D. W. (1978). Temporal factors in visual information processing. In J. Requin (Ed.), Attention and performance VII (pp. 3-23). New York: Academic Press.

ERIKSEN, C. W., \& SCHULTZ, D. W. (1979). Information processing in visual search: A continuous flow conception and experimental results. Perception \& Psychophysics, 25, 249-263.

ERIKSEN, C. W., \& St. JAMES, J. D. (1986). Visual attention within and around the field of focal attention: A zoom lens model. Perception \& Psychophysics, 40, 225-240.

ERIKSEN, C. W., WeBB, J. M., \& Fournier, L. R. (1990). How much processing do nonattended stimuli receive? Apparently very little, but... Perception \& Psychophysics, 47, 477-488.

ERIKSEN, C. W., \& YEH, Y. (1985). Allocation of attention in the visual field. Journal of Experimental Psychology: Human Perception \& Performance, 11, 583-597.

ESTES, W. K. (1972). Interactions of signal and background variables in visual processing. Perception \& Psychophysics, 12, 278-286.

ESTES, W. K. (1982). Similarity-related channel interactions in visual processing. Journal of Experimental Psychology: Human Perception \& Performance, 8, 353-382.

Estes, W. K., \& TAYLOR, H. A. (1966). Visual detection in relation to display size and redundancy of critical elements. Perception \& Psychophysics, 1, 9-16.

Flavell, J. H., \& Draguns, J. (1957). A microgenetic approach to perception and thought. Psychological Bulletin, 54, 197-217.

FLOWERS, J. H., \& WiLCOX, N. (1982). The effect of flanking context on visual classification: The joint contributions of interactions at different processing levels. Perception \& Psychophysics, 32, 581-591.

FoURNIER, L. R., \& ERIKSEN, C. W. (1990). Coactivation in the perception of redundant targets. Journal of Experimental Psychology: Human Perception \& Performance, 16, 538-550.

Francolini, C. M., \& Egeth, H. E. (1979). Perceptual selectivity is task dependent: The pop-out effect poops out. Perception \& Psychophysics, 25, 99-110.

Gratton, G., Coles, M. G. H., Sirevaag, E. J., Eriksen, C. W., \& Donchin, E. (1988). Pre- and poststimulus activation of response channels: A psychophysiological analysis. Journal of Experimental Psychology: Human Perception \& Performance, 14, 331-344.

Grice, G. R., Boroughs, J. M., \& Canham, L. (1984). Temporal dynamics of associative interference and facilitation produced by visual context. Perception \& Psychophysics, 36, 499-507.

Grice, G. R., \& CANHAM, L. (1990). Redundancy phenomena are affected by response requirements. Perception \& Psychophysics, 48, 209-213.

Grice, G. R., Canham, L., \& Boroughs, J. M. (1984). Combination rule for redundant information in reaction time tasks with divided attention. Perception \& Psychophysics, 35, 451-463.

Grice, G. R., CanHAM, L., \& Schafer, C. (1982). Development of associative and perceptual interference. Perception \& Psychophysics, 35, 451-463.

GRUNZKe, P. M. (1991). Perceptual deadtime: Is there processing latency in the perceptual system? Unpublished doctoral dissertation, University of Illinois, Urbana-Champaign.

HoFFMAN, J. E. (1975). Hierarchical stages in the processing of visual information. Perception \& Psychophysics, 18, 348-354.

JONIDES, J. (1980). Towards a model of the mind's eye's movement. Canadian Journal of Psychology, 34, 103-112.

JoNIDES, J. (1981). Voluntary versus automatic control over the mind's eye's movement. In J. B. Long \& A. D. Baddeley (Eds.), Attention and performance $I X$ (pp. 187-203). Hillsdale, NJ: Erlbaum.
JoNIDES, J., \& YANTIS, S. (1988). Uniqueness of abrupt visual onset in capturing attention. Perception \& Psychophysics, 43, 346-354.

Kahneman, D., \& ChaJzyK, D. (1983). Tests of the automaticity of reading: Dilution of Stroop effects by color-irrelevant stimuli. Journal of Experimental Psychology: Human Perception \& Performance, 9, 497-509.

Kahneman, D., \& Henik, A. (1981). Perceptual organization and attention. In M. Kubovy \& J. R. Pomerantz (Eds.), Perceptual organization (pp. 181-211). Hillsdale, NJ: Erlbaum.

Kahneman, D., Treisman, A., \& Burkell, J. (1983). The cost of visual filtering. Journal of Experimental Psychology, 9, 510-522.

Kramer, A. F., \& JACOBSON, A. (1991). Perceptual organization and focused attention: The role of objects and proximity in visual processing. Perception \& Psychophysics, 50, 267-284.

LAPPIN, J. S., \& UTTAL, W. R. (1976). Does prior knowledge facilitate the detection of visual targets in random noise? Perception \& Psychophysics, 20, 367-374.

LOCKHEAD, G. R. (1979). Holistic versus analytic process models: A reply. Journal of Experimental Psychology: Human Perception \& Performance, 5, 746-755.

LOGAN, G. D. (1978). Attention in character classification: Evidence for the automaticity of component stages. Journal of Experimental Psychology: General, 107, 32-63.

MilleR, J., \& HACKLEY, S. A. (1992). Electrophysiological evidence for temporal overlap among contingent mental processes. Journal of Experimental Psychology: General, 121, 195-209.

MonahaN, J. S., \& LockHEAD, G. R. (1977). Identification of integral stimuli. Journal of Experimental Psychology: General, 106, 94-110.

NeIsser, U. (1967). Cognitive psychology. Englewood Cliffs, NJ: Prentice-Hall.

PAN, K., \& ErIKSEN, C. W. (1992). Attentional distribution in the visual field during same-different judgments as assessed by response competition. Perception \& Psychophysics, 53, 134-144.

Pomerantz, J. R., \& GARNER, W. R. (1973). Stimulus configuration in selective attention tasks. Perception \& Psychophysics, 14, 565569.

Pomerantz, J. R., \& Schwaitzberg, S. D. (1975). Grouping by proximity: Selective attention measures. Perception \& Psychophysics, 18, 355-361.

SCHNEIDER, W., \& SHIFFRIN, R. M. (1977). Controlled and automatic human information processing: I. Detection, search, and attention. Psychological Review, 84, 1-62.

Treisman, A. M., \& Gelade, G. (1980). A feature-integration theory of attention. Cognitive Psychology, 12, 97-136.

Treisman, A. [M.], Kahneman, D., \& Burkell, J. (1983). Perceptual objects and the cost of filtering. Perception \& Psychophysics, 33, 527-532.

Treisman, A. [M.], \& Souther, J. (1985). Search asymmetry: A diagnostic for preattentive processing of separable features. Journal of Experimental Psychology: General, 114, 285-310.

vAN DER HeIJEN, A. H. C. (1992). Selective attention in vision. London: Routledge.

van der Heisden, A. H. C., \& Eerland, E. (1973). The effects of cueing in a visual signal detection task. Quarterly Journal of Experimental Psychology, 25, 496-503.

van der Heijden, A. H. C., Wolters, G., \& Enkeling, M. (1988). The effects of advance location cueing on latencies in a single-letter recognition task. Psychological Research, 50, 94-102.

van der Heijden, A. H. C., Wolters, G., Groep, J. C., \& HageNAAR, R. (1987). Single-letter recognition accuracy benefits from advance cuing of location. Perception \& Psychophysics, 42, 503509.

WATT, R. (1988). Visual processing: Computational, psychophysical and cognitive research. Hillsdale, $\mathrm{NJ}$ : Erlbaum.

YANTIS, S., \& Jonides, J. (1984). Abrupt visual onsets and selective attention: Evidence from visual search. Journal of Experimental Psychology: Human Perception \& Performance, 10, 601-621.

YANTIS, S., \& JONIDES, J. (1990). Abrupt visual onsets and selective attention: Voluntary versus automatic allocation. Journal of Experimental Psychology: Human Perception \& Performance, 16, 121 134. 


\section{NOTES}

1. Kahneman et al. (1983) found that a precued multielement display led to faster target detection RTs than did a noncued single element display; however, it is unclear whether precuing eliminated the distraction effect since alerting effects (due to the precue) were not equated between these two displays.

2. See Flowers and Wilcox (1982) for facilitation effects when precuing a target among redundant noise stimuli.

3. No-change control was replaced by itself at the different change delays in order to equate stimulus events, such as possible flicker across the different letter change conditions at the three change delays.

4. Scoring responses to $\mathrm{T} 1$ in the $\mathrm{T} 1-\mathrm{T} 2$ condition as errors was done in order to equate correct and error RT distributions for the $\mathrm{T} 1-\mathrm{T} 2$ and the N-T conditions. For example, if the letter change delay was $33 \mathrm{msec}$, a correct response in both the N-T and the T1-T2 conditions could not begin until after $33 \mathrm{msec}$. This is because the target in the $\mathrm{N}-\mathrm{T}$ condition and the correct target $\mathrm{T} 2$ in the $\mathrm{T} 1-\mathrm{T} 2$ condition would not be available until after $33 \mathrm{msec}$. Thus, the correct RT distributions occurred between 33 and $167 \mathrm{msec}$ for both the N-T and the $\mathrm{T} 1-\mathrm{T} 2$ conditions. Also, errors based on processing the original stimulus $\mathrm{N}$ in the $\mathrm{N}-\mathrm{T}$ and $\mathrm{T} 1$ in the $\mathrm{T} 1-\mathrm{T} 2$ conditions would occur before $33 \mathrm{msec}$ for both the N-T and the T1-T2 conditions, and errors based on the changed stimulus would occur between 33 and $167 \mathrm{msec}$. Thus, the argument that higher RTs in the T1-T2 conditions, relative to those in the $\mathrm{N}-\mathrm{T}$ conditions, were due to higher errors in the T1-T2 conditions can be ruled out. The RT distributions corresponding to the presentation time of the original stimulus and the new stimulus are equated between the $\mathrm{N}-\mathrm{T}$ and the $\mathrm{T} 1-\mathrm{T} 2$ conditions.

5. The $\mathrm{T} 1-\mathrm{T} 2$ condition appears to be slower than the control condition at a change delay of $17 \mathrm{msec}$ in the four- and eight-letter simultaneous cued displays (see Table 1); this trend, however, fell short of significance $(p>.05)$ by planned comparisons and appears to have been due to an exceptionally low RT value for the control condition. This does not appear to have been due to response interference by the original stimulus in the T1-T2 condition, since there is no difference in RT between the T1-T2 condition at the 17- and 33-msec change delay. Moreover, there is no difference between the control and T1-T2 condition at a change delay of $33 \mathrm{msec}$.

6 . The noise letter $M$ was replaced by a $W$ since the letter $M$ was visually extremely similar to the target letter $N$ in Experiment 1 . However, the results and trends found in Experiment 1 were not any different when the $N-T$ conditions containing the letter $M$ in the cued location were included or excluded from the data analyses.

(Manuscript received March 9, 1993; revision accepted for publication May 10, 1994.) 